\title{
Bazı sedatif ve anestezik aromatik bitki yağlarının gökkuşağı alabalığı (Oncorhynchus mykiss, L.) kan parametreleri üzerine etkileri
}

\author{
Mehmet Fuat GÜLHAN* \\ Aksaray Üniversitesi, Teknik Bilimler Meslek Yüksek Okulu, Bitkisel ve Hayvansal Üretim Bölümü, Tıbbi \\ ve Aromatik Bitkiler Programı, 68100-Aksaray \\ Gelis Tarihi (Recived Date): 05.04.2018 \\ Kabul Tarihi (Accepted Date): 20.04.2018
}

\section{Özet}

Bu çalışmada, geleneksel tıpta sedatif ve anestezik etkileri olduğu bilinen alıç (Crataegus monogyna), limon otu (Melissa officinalis), haşhaş (Papaver somniferum), biberiye (Rosmarinus officinalis)' den elde edilen yağların 96 saat ve $25 \mathrm{mg} / \mathrm{L}$ konsantrasyonda gökkuşağı alabalıklarının kanında (Oncorhynchus mykiss) meydana getirdiği biyokimyasal ve hematolojik değişimler belirlendi. Alıç, limon otu ve haşhaş yağı uygulanan grupların ALT (alanin aminotransferaz), ALP (alkalen fosfataz), AST (aspartat aminotransferaz), LDH (laktat dehidrogenaz), glikoz, kortizol, toplam protein, üre ve kreatinin seviyelerinde kontrol grubu ile karşılaştırıldığında istatistiksel açıdan önemli artışlar $(P<0.05)$, toplam kolesterol, trigliserid, sodyum, potasyum ve demir seviyelerinde ise önemli azalmalar $(P<0.05)$ tespit edildi. Hematolojik parametrelerde ise alıç ve haşhaş yağl uygulanan balıkların eritrosit, hemoglobin ve hematokrit seviyelerinde kontrole göre anlaml artışlar $(P<0.05)$, lökosit değerinde ise azalma $(P<0.05)$ belirlendi. Biyokimyasal ve hematolojik sonuçlar, literatürde balık anestezisinde doğal ajan olarak sıkça kullanılan karanfil yağının 25-50 mg/L konsantrasyonu ile yapılan çalışmalarda elde edilen kan parametreleri ile karşılaştırıldığında, alıç, haşhaş ve limon otunun da sedasyon ve anestezi için kullanılabileceğini ortaya koymuştur. Bu yüzden sentetik anestezikler yerine doğal anestezikler olarak $25 \mathrm{mg} / \mathrm{L}$ konsantrasyonda 96 saat uygulanan alıç, haşhaş ve limon otu yağının balıkların fizyolojik fonksiyonlarının düzenlenmesinde alternatif bir antioksidan takviyesi olarak kullantlabileceği ve onları tüketen organizmaların sağlı̆̆ına da olumlu katkılar sağlayabileceği düisünülmektedir.

Anahtar kelimeler: Crataegus monogyna, Melissa officinalis, Papaver somniferum, Rosmarinus officinalis, Rainbow trout, Sedatif etki, anestezik etki.

\footnotetext{
*Mehmet Fuat GÜLHAN, mfuatgulhan@aksaray.edu.tr, https://orcid.org/0000-0003-4838-1597
} 


\title{
Effects on the blood parameters of the rainbow trout (Oncorhynchus mykiss, L.) of some sedative and anesthetic aromatic plant oils
}

\begin{abstract}
In this study, the oil obtained from hawthorn (Crataegus monogyna), lemon balm (Melissa officinalis), opium poppy (Papaver somniferum), rosemary (Rosmarinus officinalis) known to have sedative and anesthetic efficacy in traditional medicine were determined biochemical and hematological changes in blood of rainbow throut (Oncorhynchus mykiss) in $96 \mathrm{~h}$ and a concentration of $25 \mathrm{mg} / \mathrm{L}$. There were statistically significant increases in the levels of ALT (alanin aminotransferaz), ALP (alkalen fosfataz), AST (aspartat aminotransferaz), LDH (laktat dehidrogenaz), glucose, cortisol, total protein, urea and creatinine levels in the groups treated with hawthorn, lemon balm and opium poppy when compared with the control group $(P<0.05)$ and total cholesterol, triglyceride, sodium, potassium and iron levels were found significant reductions $(P<0.05)$. In hematological parameters; there were significant increases $(P<0.05)$ in erythrocyte, hemoglobin and hematocrit levels of fish treated with hawthorn and opium poppy oil and decrease in leukocyte count $(P<0.05)$. Biochemical and hematological results have shown that hawthorn, opium poppy and lemon balm oil can also be used for sedation and anesthesia when compared to blood parameters obtained from studies with $25-50 \mathrm{mg} / \mathrm{L}$ concentration of clove oil commonly used as a natural agent in fish anesthesia. It is believed that hawthorn, opium poppy and lemon balm oil applied in concentration of $25 \mathrm{mg} / \mathrm{L}$ for $96 \mathrm{~h}$ may be used as an alternative antioxidant supplement in the regulation of the physiological functions of fish and may provide positive contributions to the health of the consuming organisms.
\end{abstract}

Keywords: Crataegus monogyna, Melissa officinalis, Papaver somniferum, Rosmarinus officinalis, Blood, Rainbow trout, sedative effect, anesthetic effect.

\section{Giriș}

Çevresel ve biyolojik etkiler organizmada çeşitli fizyolojik ve biyokimyasal değişimler meydana getirmektedir. Bu değişiklikler canlının hemopoyetik sistemi ile doğrudan ilişkilidir [1]. Balıklarda beslenme ve çevre ilişkisi, homeostatik dengenin korunmasında etkilidir. Hemeostasinin korunmasındaki bazı fizyolojik değişimler (biyokimyasal, hematolojik, hormonal ve enerji metabolizması) kan parametrelerinin değişmesine ve stres düzeyinin değerlendirilmesi konusunda önemli veriler elde edilmesine yardımcı olabilir [2]. Sucul ekosistemlerde; canlı için uygun olmayan çevre koşulları, stok yoğunluğu, gürültülü ortam şartları, nakil süreci, anestezik maddelerin uygulanması, ortamdaki anlık fiziksel ve kimyasal değişiklikler, hastalık etmenleri gibi pek çok faktörler canlılarda stres oluşumuna yol açarak hücresel bozukluklara dolayısıyla serbest radikal üretiminin artmasına neden olurlar [3]. Serbest radikaller, membranlardaki doymamış yağ asitlerinin oksidasyona neden olarak oksidatif strese yol açmaktadırlar. Diğer omurgalılarda olduğu gibi sucul canlılarda da lipid peroksidayonu sonucu oluşan MDA (malondialdehid), doymamış yağ asitlerinin oksidasyon ürünü olarak hücresel bileşenlerde meydana gelen oksidatif stresin en önemli göstergelerinden 
birisidir [4]. Balıklar ile yapılan çeşitli çalışmaların (yakalanması, taşınması, sağım, ölçüm, aşılama) daha rahat yapılabilmesi ve canlıda stres oluşturmaması için uygulanan anestezik ve sedatif maddeler, balıkları sakinleștirerek hareketsiz kalmasına dolayısıyla daha rahat çalışılabilmesine imkan vermektedir [5,6]. Akuatik organizmaların sedasyonunda kullanılan en yaygin anestezikler MS222, benzokain ve 2-fenoksi etanol, eugenol, $\mathrm{CO}_{2}$ olarak gösterilmektedir [7]. Bu anesteziklerin bazı maddeler ile birlikte kullanılması sonucu oluşan sedatif etkilerin de olduğu bilinmektedir; kinaldin sülfatdiazepam [8], ksilokain-sodyum bikarbonat [9], alfaksalon-alfadolon ve metomidat hidroklorür-gallamine triethiodide [10]. İnsan sağlı̆̆ açısından olumsuz etkilere sahip olduğu bilinen kimyasal anesteziklerin organizmada toksik kalıntılara yol açtığı belirlenmiştir [11]. Sentetik farmasötiklerin ve terapötiklerin kullanımı yerine canlılar için daha güvenli olduğu bilinen doğal bileşenlerin kullanımı tavsiye edilmektedir [12]. Balıklar ile yapılan deneysel çalışmalarda anestezik ve sedatif olarak başarılı bir şekilde uygulanmış, doğal bitkisel bir ürün olan karanfil yağı sentetik anestezikler ile kıyaslandığında her zaman iyi bir alternatif olmuş ve yeni bitkisel sedatif-anestezik maddelerin ortaya çıkartılmasına kılavuzluk etmiştir. Balık anestezisinde kullanılmak üzere karanfil yağı [13], nane yağı [14], kekik yağı [15] ve lavanta yağ1 [16] gibi bitkisel yağlardan elde edilen doğal ajanlar üzerine çalışmalar gerçekleştirildiği bilinmektedir. Sedatif ve anestezik etkileri yapılan çalışmalar ile ortaya konulan; alıç [17], limon otu [18], haşhaş [19], biberiye [20] bitki yağlarının balık materyalinde süre ve doz miktarının araştırıldığı bir çalışmaya rastlanmamıştır. Bu nedele sedatif ve anestezik bitki yağlarının konsantrasyonuna ve balıkların bu konsantrasyona hangi süreyle maruz kaldıklarına bağlı olarak kan indekslerindeki değişimler ile bunların fizyolojik önemleri bu çalışma ile ortaya konulmaya çalışılmıştır.

\section{Materyal ve metot}

\subsection{Deneysel gruplar ve uygulama esaslart}

Gökkuşağı alabalıklarına sedatif ve anestezik ekili yağ ekstraktlarının uygulanması sonucu biyokimyasal ve hematolojik değişiklikleri gözlemlemek amacıyla; 5 farklı deney grubuna ait her akvaryumda 7 balık olacak şekilde toplam 35 adet alabalık kullanılmıştır. Niğde-Çamardı Ecemiş Alabalık Üretim Tesislerinden temin edilen alabalıklar, 200 L'lik akvaryumlara konularak 10-15 gün boyunca ortama adaptasyonları sağlanmıştır. Çalışma grupları; kontrol grubu, $25 \mathrm{mg} / \mathrm{L}$ alıç yağı, 25 $\mathrm{mg} / \mathrm{L}$ limon otu yağı, $25 \mathrm{mg} / \mathrm{L}$ haşhaş yağ 1 ve $25 \mathrm{mg} / \mathrm{L}$ biberiye yağı grupları şeklinde oluşturulmuştur. Çalışmada kullanılan alabalıkların ortalama ağırlıkları 250.24 $\pm 4.88 \mathrm{~g}$, ortalama uzunlukları ise $28.25 \pm 4.34 \mathrm{~cm}$ olarak belirlenmiştir. Ayrıca deneyde kullanılan suyun fizikokimyasal özellikleri de çalışma için büyük önem arz ettiği için, suyun pH derecesi $7.6 \pm 0.4$ sıcaklığı ise $12.1 \pm 0.3{ }^{\circ} \mathrm{C}$ 'de tutulmaya çalışılmıştır. Uygulama öncesi ve sonrası suyun diğer özellikleri de tablo 1 'de verilmiştir. 
Tablo 1. Uygulama öncesi ve sonrası belirlenen su kriterleri.

\begin{tabular}{lll}
\hline Parametreler & Uygulama Öncesi & Uygulama sonrası \\
\hline Çözünmüş oksijen $(\mathrm{ppm})$ & $7.6 \pm 0.6$ & $7.4 \pm 0.3$ \\
Kimyasal oksijen ihtiyacı $(\mathrm{ppm})$ & $13.1 \pm 0.4$ & $15.5 \pm 0.8$ \\
Askida kalan maddeler $(\mathrm{ppm})$ & $37.6 \pm 1.5$ & $41.1 \pm 1.2$ \\
Kalsiyum $(\mathrm{ppm})$ & $132.0 \pm 1.8$ & $109.1 \pm 1.5$ \\
Sodyum $(\mathrm{ppm})$ & $24.4 \pm 0.4$ & $17.7 \pm 0.3$ \\
Klor $(\mathrm{ppm})$ & $15.0 \pm 1.2$ & $16.0 \pm 1.8$ \\
Total azot $(\mathrm{ppm})$ & $5.3 \pm 0.5$ & $6.2 \pm 0.7$ \\
Sertlik $\left(\mathrm{CaCO}_{3}\right)(\mathrm{ppm})$ & $179.3 \pm 3.6$ & $163.2 \pm 2.3$ \\
Sicaklı $\left({ }^{\circ} \mathrm{C}\right)$ & $12.5 \pm 1.6$ & $12.1 \pm 0.3$ \\
pH & $7.6 \pm 0.3$ & $7.6 \pm 0.4$ \\
& & \\
\hline
\end{tabular}

\subsection{Bitki ekstraktlarının hazırlanması}

Kurutulmuş ve öğütülmüş bitki örneklerinden $40 \mathrm{~g}$ alınarak soxhlet cihazının haznesindeki kartuşa yerleştirildi ve $n$-hekzan ile 4 saat boyunca yağ ekstraktı çıkarma işlemi yapıldı. Bitki yağ özütleri süzüldükten sonra etanol, vakum altında rotary evaporatörde $40{ }^{\circ} \mathrm{C}$ 'de buharlaştırıldı ve analiz edilinceye kadar $+4{ }^{\circ} \mathrm{C}$ de bekletildi [21].

\subsection{Numune temini, saklama koşulları, biyokimyasal ve hematolojik analizler}

Çalışmada kullanılan alabalıklara ekstra olarak anestezik madde uygulanmamıştır. Kuru bir havlu ile silinen balıkların kuyruk yüzgecinin 1-2 cm gerisinden keskin bir biçakla kesilip 'kuyruk venasın'dan direkt olarak içerisinde jel bulunan cam tüplere 2 ml kadar kan alınmasıyla gerçekleştirildi. Balıklardan alınan kan direkt olarak plazma için EDTA'lı tüplere, serum için ise steril plastik tüplere alınarak 3500 g'de 10 dakika santrifüj edilerek serum ve plazma kısımları ayırıldı. Elde edilen örnekler analiz edilene kadar $-20^{\circ} \mathrm{C}^{\prime}$ de muhafaza edildi [22]. Kan parametrelerindeki değişimler Roche Hitachi Cobas 8000 marka otoanalizör cihazı ile belirlendi.

\section{4. Ístatistiksel analizler}

Ortalamalar arasındaki farkların istatistiksel anlamlılık düzeylerini belirlemek için SPSS 21.0 paket istatistik programı kullanıldı. İstatistiksel farklar bağımsız gruplarda "Oneway ANOVA" ve gruplar arasındaki farklılıkları belirlemek için çoklu karşılaştırmalı Duncan Testi kullanıldı. Elde edilen sonuçlar ortalama \pm standart sapma olarak verildi ve $P<0.05$ değeri istatistiksel olarak anlamlı kabul edildi.

\section{Bulgular}

Gökkuşağı alabalıklarında (Oncorhynchus mykiss) kontrol grubu, 96 saat boyunca 25 $\mathrm{mg} / \mathrm{L}$ konsantrasyonlarda dört farklı (Crataegus monogyna, Melissa officinalis, Papaver somniferum, Rosmarinus officinalis) sedatif-anestezik bitki yağı uygulanması sonucu, serum enzimatik parametrelerindeki değişimler tablo 2'de gösterilmiştir. Alıç, limon otu, haşhaş yağları uygulanan gökkuşağı alabalıklarının kan enzimatik parametreleri kontrol grubu ile karşılaştırıldığında, ALT ve ALP değerlerinde istatistiksel olarak önemli artışlar tespit edilirken $(P<0.05)$, biberiye yağı uygulanan alabalıklarda bu parametrelerde istatistiksel olarak önemli bir değişimin olmadığı 
belirlenmiştir. AST değerleri karşılaştırıldığında kontrol grubuna göre dört farklı bitkinin yağ ekstraktları uygulanan alabalıklarda istatistiksel olarak önemli artışlar tespit edilmiştir $(P<0.05)$. LDH değeri haşhaş yağı uygulanan alabalıklarda kontrole göre istatistiksel olarak önemli artış göstermiş $(P<0.05)$, alıç, limon otu ve biberiye yağlarının uygulanması bu parametrede istatistiksel olarak bir önem arz etmemiştir.

Tablo 2. Eşit konsantrasyonlarda (25 mg/L) Crataegus monogyna, Melissa officinalis, Papaver somniferum, Rosmarinus officinalis yağları uygulanan alabalık kan serumlarındaki enzimatik parametreler

\begin{tabular}{|c|c|c|c|c|c|}
\hline $\begin{array}{c}\text { Enzimler } \\
\text { (IU/L) }\end{array}$ & Kontrol & $\begin{array}{c}\text { ALIÇ } \\
\text { Crataegus } \\
\text { monogyna } \\
(25 \mathrm{mg} / \mathrm{L})\end{array}$ & $\begin{array}{c}\text { LiMON OTU } \\
\text { Melissa } \\
\text { officinalis } \\
(25 \mathrm{mg} / \mathrm{L})\end{array}$ & $\begin{array}{l}\text { HAŞHAŞ } \\
\text { Papaver } \\
\text { somniferum } \\
(25 \mathrm{mg} / \mathrm{L})\end{array}$ & $\begin{array}{c}\text { BiBERiYE } \\
\text { Rosmarinus } \\
\text { officinalis } \\
(25 \mathrm{mg} / \mathrm{L})\end{array}$ \\
\hline ALT & $34.7 \pm 1.4^{\mathrm{c}}$ & $45.16 \pm 2,1^{b}$ & $53.50 \pm 0.6^{\mathrm{a}}$ & $54 \pm 0.8^{\mathrm{a}}$ & $32.66 \pm 1.4^{\mathrm{c}}$ \\
\hline ALP & $52.5 \pm 2.7^{\mathrm{c}}$ & $71.33 \pm 2,5^{\mathrm{b}}$ & $72.48 \pm 0.1^{\mathrm{b}}$ & $86.56 \pm 1.2^{\mathrm{a}}$ & $50.5 \pm 3.2^{c}$ \\
\hline AST & $585 \pm 6.5^{\mathrm{c}}$ & $698.40 \pm 4,6^{\mathrm{a}}$ & $640.12 \pm 3,5^{\mathrm{a}}$ & $591.8 \pm 5.2^{\mathrm{b}}$ & $607 \pm 7.3^{\mathrm{b}}$ \\
\hline LDH & $786.2 \pm 40.2^{b}$ & $782.66 \pm 25.4^{\mathrm{b}}$ & $794.25 \pm 34.2^{\mathrm{b}}$ & $923.20 \pm 13.4^{\mathrm{a}}$ & $75.50 \pm 32.1^{b}$ \\
\hline
\end{tabular}

$a, b, c$ her satırda veya sütunda farklı harflerle gösterilen rakamlar olmak üzere istatistiksel olarak birbirinden farklıdır $(P<0.05)$. Tabloda verilen değerler ortalama \pm standart hata $(n=7)$ değeri olarak ifade edilmektedir.

Gökkuşağı alabalıklarında (Oncorhynchus mykiss) kontrol grubu, 96 saat boyunca 25 $\mathrm{mg} / \mathrm{L}$ konsantrasyonlarda dört farklı (Crataegus monogyna, Melissa officinalis, Papaver somniferum, Rosmarinus officinalis) sedatif-anestezik bitki yağı uygulanması sonucu, kan metabolitlerindeki değişimler tablo 3'de gösterilmiştir. Sedatif ve anestezik bitki yağları uygulandığı tüm gruplarda alabalıkların kortizol, glikoz, üre değerlerinin, kontrol grubuna göre istatistiksel olarak önemli $(P<0.05)$ düzeyde artış gösterdiği belirlenmiştir. Toplam kolesterol ve trigliserid değerleri ise yağ ekstraktı uygulanan tüm gruplarda kontrole göre önemli $(P<0.05)$ seviyelerde azalma olduğu tespit edilmiştir. Toplam protein ve kreatinin düzeyleri; alıç, limon otu, haşhaş yağları uygulanan alabalıklarda kontrol grubuna göre önemli düzeyde artarken $(P<0.05)$, biberiye yağı alabalıklarda bu parametrelerde istatistiksel olarak anlamlı bir fark yaratmamıştır. 
Tablo 3. Eşit konsantrasyonlarda (25 mg/L) Crataegus monogyna, Melissa officinalis, Papaver somniferum, Rosmarinus officinalis yağları uygulanan alabalık kan serumlarındaki metabolitler

\begin{tabular}{|c|c|c|c|c|c|}
\hline Metabolitler & Kontrol & $\begin{array}{c}\text { ALIÇ } \\
\text { Crataegus } \\
\text { monogyna } \\
(25 \text { mg/L) }\end{array}$ & $\begin{array}{c}\text { LiMON OTU } \\
\text { Melissa } \\
\text { officinalis } \\
(25 \mathrm{mg} / \mathrm{L})\end{array}$ & $\begin{array}{l}\text { HAŞHAŞ } \\
\text { Papaver } \\
\text { somniferum } \\
(25 \mathrm{mg} / \mathrm{L})\end{array}$ & $\begin{array}{c}\text { BiBERiYE } \\
\text { Rosmarinus } \\
\text { officinalis } \\
(25 \mathrm{mg} / \mathrm{L})\end{array}$ \\
\hline $\begin{array}{c}\text { Glukoz } \\
\text { (mg/dL) }\end{array}$ & $65.7 \pm 0.3^{c}$ & $75.66 \pm 0.8^{b}$ & $81.24 \pm 1.2^{\mathrm{a}}$ & $85.34 \pm 1.3^{\mathrm{a}}$ & $73.83 \pm 0.9^{b}$ \\
\hline $\begin{array}{c}\text { Toplam } \\
\text { kolesterol } \\
(\mathrm{mg} / \mathrm{dL}) \\
\end{array}$ & $174.6 \pm 15.3^{\mathrm{a}}$ & $128.50 \pm 9.5^{\mathrm{c}}$ & $146.40 \pm 5.3^{\mathrm{b}}$ & $126.75 \pm 0.9^{c}$ & $156 \pm 0.4^{\mathrm{c}}$ \\
\hline $\begin{array}{l}\text { Kortizol } \\
\text { (ng/mL) }\end{array}$ & $16.54 \pm 1.18^{\mathrm{c}}$ & $21.44 \pm 1.3^{\mathrm{b}}$ & $26.84 \pm 4.2^{\mathrm{b}}$ & $28.12 \pm 0.7^{\mathrm{a}}$ & $20.23 \pm 1.6^{\mathrm{b}}$ \\
\hline $\begin{array}{c}\text { Trigliserid } \\
\text { (mg/dL) }\end{array}$ & $356.2 \pm 36.2^{\mathrm{a}}$ & $161.66 \pm 2.8^{c}$ & $164.62 \pm 4.2^{\mathrm{c}}$ & $167.06 \pm 3.7^{c}$ & $244.2 \pm 4.6^{\mathrm{b}}$ \\
\hline $\begin{array}{l}\text { Toplam } \\
\text { protein } \\
(\mathrm{mg} / \mathrm{dL}) \\
\end{array}$ & $2.59 \pm 0.1^{\mathrm{b}}$ & $3.5 \pm 0.8^{\mathrm{a}}$ & $3.56 \pm 0.5^{\mathrm{a}}$ & $3.91 \pm 1.1^{\mathrm{a}}$ & $2.68 \pm 1.6^{\mathrm{b}}$ \\
\hline Üre (mg/dL) & $4.7 \pm 0.8^{\mathrm{c}}$ & $9.73 \pm 0.7^{b}$ & $12.03 \pm 0.2^{\mathrm{a}}$ & $12.56 \pm 1.2^{\mathrm{a}}$ & $9.43 \pm 1.6^{\mathrm{b}}$ \\
\hline $\begin{array}{c}\text { Kreatinin } \\
\text { (mg/dL) }\end{array}$ & $0.12 \pm 0.004^{\mathrm{c}}$ & $0.21 \pm 0.007^{\mathrm{a}}$ & $0.18 \pm 0.003^{\mathrm{b}}$ & $0.24 \pm 0.004^{\mathrm{a}}$ & $0.14 \pm 0.005^{\mathrm{c}}$ \\
\hline
\end{tabular}

$a, b, c$ her satırda veya sütunda farklı harflerle gösterilen rakamlar olmak üzere istatistiksel olarak birbirinden farklıdır $(P<0,05)$. Tabloda verilen değerler ortalama \pm standart hata $(n=7)$ değeri olarak ifade edilmektedir.

Gökkuşağı alabalıklarında (Oncorhynchus mykiss) kontrol grubu, 96 saat boyunca 25 $\mathrm{mg} / \mathrm{L}$ konsantrasyonlarda dört farklı (Crataegus monogyna, Melissa officinalis, Papaver somniferum, Rosmarinus officinalis) sedatif-anestezik bitki yağı ekstraktı uygulanması sonucu, kan serumu elektrolitlerindeki değişimler tablo 4'de gösterilmiştir. Alıç, limon otu, haşhaş ve biberiye yağı uygulanan alabalıkların sodyum, potasyum ve demir seviyeleri kontrol grubu ile karşılaştırıldığında istatistiksel olarak önemli azalmaların olduğu $(P<0.05)$, kalsiyum değerlerinin bu bitki yağları uygulanan gruplarda kontrol grubu değeri arasında istatistiksel bir farkın olmadığı tespit edilmiştir.

Tablo 4. Eşit konsantrasyonlarda (25 mg/L) Crataegus monogyna, Melissa officinalis, Papaver somniferum, Rosmarinus officinalis yağları uygulanan alabalık kan serumlarındaki elektrolitler

\begin{tabular}{|c|c|c|c|c|c|}
\hline $\begin{array}{c}\text { Elektrolitler } \\
(\mathbf{m m o l} / \mathbf{L})\end{array}$ & Kontrol & $\begin{array}{c}\text { ALIÇ } \\
\text { Crataegus } \\
\text { monogyna } \\
(\mathbf{2 5} \mathbf{~ m g} / \mathbf{L})\end{array}$ & $\begin{array}{c}\text { LiMON OTU } \\
\text { Melissa } \\
\text { officinalis } \\
(\mathbf{2 5} \mathbf{~ m g} / \mathbf{L})\end{array}$ & $\begin{array}{c}\text { HAŞHAŞ } \\
\text { Papaver } \\
\text { somniferum } \\
(\mathbf{2 5} \mathbf{~ m g} / \mathbf{L})\end{array}$ & $\begin{array}{c}\text { BiBERiYE } \\
\text { Rosmarinus } \\
\text { officinalis } \\
(\mathbf{2 5} \mathbf{~ m g} / \mathbf{L})\end{array}$ \\
\hline Sodyum & $151.6 \pm 2.5^{\mathrm{a}}$ & $108.33 \pm 2.7^{\mathrm{c}}$ & $138.11 \pm 3.2^{\mathrm{b}}$ & $106.66 \pm 3.8^{\mathrm{c}}$ & $127 \pm 2.2^{\mathrm{b}}$ \\
\hline Potasyum & $3.8 \pm 0.6^{\mathrm{a}}$ & $1.28 \pm 0.8^{\mathrm{b}}$ & $1.31 \pm 0.6^{\mathrm{b}}$ & $1.46 \pm 0.6^{\mathrm{b}}$ & $1.16 \pm 0.2^{\mathrm{b}}$ \\
\hline Kalsiyum & $3.8 \pm 0.4$ & $3.73 \pm 1.2$ & $3.75 \pm 2.4$ & $3.31 \pm 0.5$ & $3.86 \pm 1.9$ \\
\hline Demir & $73.3 \pm 4.3^{\mathrm{a}}$ & $48.12 \pm 3.2^{\mathrm{c}}$ & $50.5 \pm 4.4^{\mathrm{c}}$ & $62.42 \pm 4.3^{\mathrm{b}}$ & $58.55 \pm 2.9^{\mathrm{b}}$ \\
\hline
\end{tabular}


$a, b, c$ her satırda veya sütunda farklı harflerle gösterilen rakamlar olmak üzere istatistiksel olarak birbirinden farklıdır $(P<0.05)$. Tabloda verilen değerler ortalama \pm standart hata $(n=7)$ değeri olarak ifade edilmektedir.

Gökkuşağ 1 alabalıklarında (Oncorhynchus mykiss) kontrol grubu, 96 saat boyunca 25 $\mathrm{mg} / \mathrm{L}$ konsantrasyonlarda dört farklı (Crataegus monogyna, Melissa officinalis, Papaver somniferum, Rosmarinus officinalis) sedatif-anestezik bitki yağı ekstraktı uygulanması sonucu, hematolojik değişimler tablo 4'de gösterilmiştir. Kandaki eritrosit sayısı, hemoglobin ve hematokrit düzeylerinin alıç, limon otu ve haşhaş yağı uygulanan gruplarda kontrole göre istatistiksel olarak önemli seviyede artış gösterdiği $(P<0.05)$, toplam lökosit değerinin ise tüm bitki yăg ekstraktı uygulanan gruplarda kontrol grubuna göre azaldığ $(P<0.05)$ tespit edilmiştir.

Tablo 5. Eşit konsantrasyonlarda (25 mg/L) Crataegus monogyna, Melissa officinalis, Papaver somniferum, Rosmarinus officinalis yağları uygulanan alabalık kanında hematolojik parametreler

\begin{tabular}{|c|c|c|c|c|c|}
\hline $\begin{array}{l}\text { Hematalojik } \\
\text { parametreler }\end{array}$ & Kontrol & $\begin{array}{c}\text { ALIÇ } \\
\text { Crataegus } \\
\text { monogyna } \\
(25 \mathrm{mg} / \mathrm{L})\end{array}$ & $\begin{array}{c}\text { LiMON OTU } \\
\text { Melissa } \\
\text { officinalis } \\
(25 \mathrm{mg} / \mathrm{L})\end{array}$ & $\begin{array}{l}\text { HAŞHAŞ } \\
\text { Papaver } \\
\text { somniferum } \\
(25 \mathrm{mg} / \mathrm{L})\end{array}$ & $\begin{array}{c}\text { BiBERiYE } \\
\text { Rosmarinus } \\
\text { officinalis } \\
(25 \mathrm{mg} / \mathrm{L})\end{array}$ \\
\hline $\begin{array}{c}\text { Eritrosit sayısı } \\
\quad\left(10^{6} / \mathrm{mm}^{3}\right)\end{array}$ & $1.8 \pm 0.8^{\mathrm{b}}$ & $2.18 \pm 1.2^{\mathrm{a}}$ & $2.30 \pm 1.4^{\mathrm{a}}$ & $2.38 \pm 2.6^{\mathrm{a}}$ & $2.27 \pm 3.4^{\mathrm{a}}$ \\
\hline $\begin{array}{c}\text { Hemoglobin } \\
\text { (g/dL) }\end{array}$ & $8.1 \pm 0.7^{\mathrm{c}}$ & $11.51 \pm 0.9^{\mathrm{b}}$ & $11.92 \pm 1.5^{\mathrm{a}}$ & $12.23 \pm 1.1^{\mathrm{a}}$ & $8.18 \pm 0.3^{c}$ \\
\hline $\begin{array}{c}\text { Hematokrit } \\
(\%)\end{array}$ & $32.4 \pm 2.3^{\mathrm{b}}$ & $41.53 \pm 2.4^{\mathrm{a}}$ & $43.47 \pm 3.7^{\mathrm{a}}$ & $43.26 \pm 2.2^{\mathrm{a}}$ & $37.06 \pm 3.2^{\mathrm{b}}$ \\
\hline $\begin{array}{c}\text { Toplam } \\
\text { Lökosit } \\
\left(\mathbf{m m}^{3} / \mathbf{1 0}^{3}\right)\end{array}$ & $7.75 . \pm 2.3^{\mathrm{a}}$ & $6.50 \pm 3.2^{\mathrm{b}}$ & $6.21 \pm 3.3^{\mathrm{b}}$ & $5.73 \pm 2.7^{b}$ & $6.38 \pm 3.2^{\mathrm{b}}$ \\
\hline
\end{tabular}

$a, b, c$ her satırda veya sütunda farklı harflerle gösterilen rakamlar olmak üzere istatistiksel olarak birbirinden farklıdır $(P<0.05)$. Tabloda verilen değerler ortalama \pm standart hata $(n=7)$ değeri olarak ifade edilmektedir.

\section{Tartışma ve sonuç}

Balıklarda sedatif veya anestezik ürünlerin seçiminde, düşük konsantrasyonlarda etkili olabilme, temin kolaylığı, kanserojen madde içermeme daha da önemlisi balıkların doku ve organlarında birikerek tüketimi esnasında problem teşkil etmemesi önemlidir $[23,24]$. Balık anestezisinde kullanılan bitki yağ ekstraktları farklı balık türlerinde 25$200 \mathrm{mg} / \mathrm{L}$ gibi geniş bir konsantrasyon aralığında kullanılmaktadır [25-29]. Bu çalışmada uygulanan bitki yağ ekstraktlarının uygulama dozu yapılan çalışmalar referans alınarak en düşük doz olan $25 \mathrm{mg} / \mathrm{L}$ olarak belirlenmiştir. Ayrıca, bitki yăg ekstraktlarının uygulama süresi balıklara uygulanan maddelerin organizmada etkisinin biyokimyasal ve hematolojik parametrelere akut olarak yansıdığı en uygun süre olan 96 saat olarak belirlenmiştir [30-32]. Çalışmada, serum AST, ALT, ALP düzeylerinde alıç, limon otu ve haşhaş yağı uygulanan alabalıklarda kontrole göre artış gösterirken, LDH seviyesi sadece alıç yağı verilen grupta kontrole göre istatistiksel olarak artmıştır. Bu parametrelerin kanda artması membran geçirgenliğinin bozulması ve karaciğerden salınan bu enzimlerin direk olarak kana geçmesinden kaynaklandığı düşünülmektedir. Ayrıca uygulanan bitki yağları kandaki oksijen miktarının düşmesine ve hipoksik koşulların ortaya çıkmasına neden olmuş olabilir [33]. Glikoz seviyeleri sucul organizmalardaki fizyolojik durumu belirleyen en hassas indekslerden birisidir. Artan konsantrasyonları balığın enerji kaynaklarını yoğun bir şekilde kullandığının 
göstergesidir [34]. Balıklar daha etkili şekilde oksitleme yeteneğine sahip olmaları sebebiyle, enerji kaynağı olarak glikoz yerine daha çok deamine olmamış amino asitleri kullanırlar. Buna neden olarak da biyokimyasal ve fizyolojik yapılarının karbonhidratları iyi değerlendirebilecek kapasitede olmaması gösterilmektedir [35]. Keleştemur ve Özdemir [36] gökkuşağı alabalığı yavrularına uyguladıkları anestezik maddenin glikoz ve kortizol seviyelerini arttırdığını belirttiler. Danli ve ark. [37] akut stres oluşturdukları Ctenopharyngodon idella' ya uyguladıkları anestezi sonrasında kan glikoz, kortizol ve LDH seviyelerinde anlamlı artışların olduğunu tespit ettiler. Pirhonen ve Schreck [38] alabalıklara uyguladıkları anestezikler (MS-222, karanfil yağı ve $\mathrm{CO}_{2}$ ) ile 48 saatin sonunda kortizol seviyelerinin kontrole göre artış gösterdiğini ve sentetik bir madde olan MS-222 yerine doğal anestezik olan karanfil yağının tercih edilebileceğinin sonucuna vardılar. Yapılan çalışmada da alabalık kan glikoz ve kortizol seviyelerinin sedatif etkili bitki yağlarının uygulamalarında kontrol grubuna göre arttığ en yüksek değerlerin limon otu ve haşhaş yağında olduğu belirlenmiştir. Kandaki toplam protein, üre ve kreatinin seviyeleri birbirini etkileyen göstergelerdir. Toplam protein ve üre düzeyleri alıç, limon otu, haşhaş ve biberiye yağı verilen balıklarda bu parametreleri önemli düzeyde arttırmıştır. Kreatinin seviyesi biberiye yağı uygulanan balıklar dışındaki diğer gruplarda kontrole göre artmıştır. Balıkların plazma veya serumlarındaki üre miktarlarındaki artışın uygulanan yağların meydana getirdiği sedasyon sonucu solungaçların görevini tam olarak yapamaması ile ilgili olabilir. Protein metabolizmasına bağlı olarak yapılan incelemelerde gökkuşağı alabalıklarında plazma üre miktarına besleme diyetlerinin etkileri olduğu bildirilmiştir [39]. Anestezi etkisi ile böbreklerde glomeruler filtrasyon ve tübüler fonksiyonların zayıfladığı bunun sonucu olarak ürenin uzaklaştırılamadığı ve kanda seviyesinin artışı ile kendini göstermiş olabilir. Artan kreatinin değerleride glomerular filtrasyonun azalmasına dolayısıyla renallerin görevini yapamamasıyla ilişkili olduğu düşünülmektedir. Ayrıca balıklarda kreatinin artışına neden olan durumlardan biriside su ortamındaki oksijenin azalması da gösterilebilir. Balıklarda toplam protein konsantrasyonlarındaki artış; meydana gelen sedatif etkinin organizmada enerjinin düzensiz harcanması ve absorpsiyonun düzenli yapılamaması ile ilgili olabileceği düşünülmektedir. Kandaki trigliserit ve toplam kolesterol konsantrasyonları arasında pozitif bir korelasyon mevcuttur [40]. Mevcut çalışmada elde edilen trigliserit ve toplam kolesterol seviyeleri, uygulanan bitki yağ ekstraktların bu değerlerde azalmaya yol açtığını göstermiştir. Uygulanan bitki yağlarının meydana getirdiği sedasyonun balıkların trigliserit seviyelerinde azalmaya yol açtığı durumun oluşan anestezi etkisi ile balıkların yeterli beslenememesi sonucu ortaya çıkmış olabileceği sonucuna varılmıştır. Velisek ve Svobodova [41] aynalı sazanlara (Cprinus carpio) anestezik olarak 2-phenoxyethanol uygulayarak anestezi öncesi ve sonrası serum trigliserit ve toplam kolesterol seviyelerinin kontrole göre önemli fark yaratmadığını belirtmişler. Sonuçların yapılan çalışma ile paralellik göstermemesinin sebebi anestezi süresi ve uygulanan doz ile ilgili olabilir. Doğal anestezik bitki yağları uygulanan grupların serumlarında sodyum, potasyum ve demir değerlerinin, kontrol grubuna göre önemli oranda düştük olduğu gözlenmiştir. Keleştemur ve Özdemir [36] yaptıkları çalışmada gökkuşağı alabalığı yavrularına uyguladıkları anestezik maddenin soydum ve potasyum değerlerinde istatistik olarak azalttığını ortaya koydular. Simões ve ark. [42] Oreochromis niloticus' a uyguladıkları karanfil yağının $1.8 \mathrm{mg} / \mathrm{L}$ konsantrasyonda 96 saat sonunda $\mathrm{Na}$ ve $\mathrm{K}$ seviyelerinde önemli azalmalar tespit ettiler. Davidson ve ark. [43] sentetik (AQUI-S) bir madde uyguladıkları alabalıkların kan sodyum ve potasyum değerlerini, anestezi sonrası elde edilen verilerde bu parametrelerde uygulanmadan önceki seviyelerine göre daha düşük olduğunu saptamışlar. Velisek ve ark. [44] yayın balığı (Silirus glanis) ile 
yaptıkları çalışmada serum kalsiyum seviyelerinin anestezi öncesi ve sonrasında değişmediğini, başka bir çalışmada Velisek ve Svobodova [37], 2-phenoxyethanol ile anestezi edilen aynalı sazan (Cprinus carpio) balığında, anestezi edilen grubun kan $\mathrm{Ca}$ anestezi uygulanmayan grubun serum kalsiyum değerinin istatistiksel olarak değişmediğini belirtmişlerdir. Bu araştırmacıların yaptığ çalışmalar mevcut çalışmada elde edilen sonuçları desteklemektedir. Eritrosit sayısının, kandaki oksijen miktarının azalması [45] ve dehidrasyon durumlarında [46] artış göstererek organizmanın verdiği sekonder cevap olduğu bildirilmiştir [31]. Kandaki oksijen taşınma kapasitesi, hemoglobinin ve eritrositlerin sayısı ile doğrudan ilişkilidir. Kanın oksijen bağlama kapasitesini artıran hemoglobin ayrıca karbondioksit taşıma ve kan pH'sını dengeleme de önemlidir [47]. Hematokrit düzeyleri, balığın osmotik dengesizlik yaşadığı ve iyonik değişimin düzenlendiği sistemlerin düzensizliğine bağlı olarak artış gösterebilir. Anestezi altında salgılanan adrenalin dalağın kasılmasına ve eritrositlerin kana karışmasına neden olarak hematokrit değerini arttırmış olabilir [31]. Bir diğer çalışmada Pagrus auratus' a $60 \mathrm{mg} / \mathrm{L}$ MS-222 sentetik anestezik uygulaması sonucu eritrosit ve hematokrit seviyelerininde kontrol grubuna göre artış tespit ettiler [48]. Balıklar ile yapılan çalışmalarda tıbbi bitkilerin alkoloidleri, flavonoidleri, pigmentleri, fenolik içerikleri, terpenoidleri, steroidleri ve uçucu yağlarının yemlerine veya su ortamlarına ilave edilerek büyüme performansı, yemden yararlanma, yaşama oranı, antimikrobiyolojik etkiler, antioksidan aktivite ve çevresel stres gibi pek çok parametre değerlendirilmiştir. Günümüzde bitkisel ürünlerden elde edilen farklı yağların sedatif ve anestezik özelliklerinin araştırılması da günden güne artış göstermiştir. Doğal anestezikler ile balıklar üzerinde yapılan in vivo araştırmalarda stres önleyici etkilerinin de olduğu bildirilmiş ve sentetik anesteziklere karşı daha doğru bir seçenek olacağı düşünüldüğünden bundan sonra da yeni doğal sedatif etkiye sahip bitki ekstraktlarının arayışları sürdürülmelidir. Bu ürünler antioksidan özellikleri ile balık hastalıklarını önlemede ve fizyolojik durumlarının stabilitesinde de önemli etkiler yaratacağ düşünülmektedir. Sonuç olarak, balıklarda doğal ve sentetik anestezik madde uygulamaları sonucu kan parametrelerindeki değişimlerin incelendiği çalışmalar ile bu çalışma karşılaştırıldığında gökkuşağı alabalıklarına 96 saat ve $25 \mathrm{mg} / \mathrm{L}$ dozda alıç, limon otu, haşhaş yağlarının doğal anestezi de kullanılabileceğini söylenebilir. Bundan sonra yapılacak çalışmalarda bu bitki yağları kullanılarak farklı balık türü, anestezi süresi ve dozu gibi parametreler değiştirilerek bu alandaki çalışmalar zenginleştirilebilir.

\section{Teşekkür}

$\mathrm{Bu}$ çalışmanın gerçekleşmesinde yardım ve desteklerinden dolayı Prof. Dr. Zeliha SELAMOĞLU ve Cihan DÜŞGÜN'e teşekkür ederim.

\section{Kaynaklar}

[1] Dobsikova, R., Velisek, J., Wlasow, T., Gomulka, P., Svobodova, Z., ve Novotny, L., Effects of cypermethrin on some haematological, biochemical and histopathological parameters of common carp (Cyprinus carpio L.), Neuro Endocrinology Letters, 27(suppl.2), 91-95,2006.

[2] Dönmez, E.A., Kolay, M., Özkan, F., ve Koyuncu, C.E., FMC ve malaşit yeşili sağaltım dozlarının (Oreochromis niloticus L., 1758)'un bazı kan parametrelerinde meydana getirdiği değişimler, Journal of Fisheries Aquatic Sciences, 23(1/1), 61-64, (2006). 
[3] Parveen, S., Bharose, R., ve Singh, D., Effect of tannery waste water on lactate dehydrogenase (LDH) enzyme activity of fresh water fish, Channa punctatus, Journal of Entomology and Zoology Studies, 5(2), 643-647, (2017).

[4] Talas, Z.S., Gulhan, M.F., Erdogan, K., ve Orun, I., 2014. Antioxidant effects of propolis on carp Cyprinus carpio exposed to arsenic: biochemical and histopathologic findings, Diseases of Aquatic Organims, 108, 241-249, (2014).

[5] Cooke, S.J., Suski, C.D., Ostrand, K.G., Tafts, B.L., ve Wahl, DH., Behavioural and physiological assessment of low concentrations of clove oil anaesthetic for handling and transportating large mouth bass Micropterus salmoides, Aquaculture, 239, 509-529, (2004).

[6] Hajek, G.J., Klyszejko, B., ve Dziaman, R., The anaesthetic effect of clove oil on common carp, Cyprinus carpio L, Acta Ichthyologica et Piscatoria, 36(2), 9397, (2006).

[7] Trushenski, J.T., Bowker, J.D., Cooke, S.J., Erdahl, D., Bell, T., MacMillan, J.R., Yanong, R.P., Hill, J.E., Fabrizio, M.C., Garvey, J.E., ve Sharon, S., Issues Regarding the use of sedatives in fisheries and the need for immediate-release options, Transactions of the American Fisheries Socciety, 142, 156-170, (2013).

[8] Yanar, M., ve Genç, E., Anaesthetic effects of quinaldine sulphate together with the use of diazepam on Oreochromis niloticus L. 1758 (Cichlidae) at different temperatures, Turkish Journal of Veterinary and Animal Sciences, 28(6), 1001-1005, (2004).

[9] Meza, S., Immobilization of carp (Cyprinus carpio), catfish (Ictalurus punctatus) and tilapia (Tilapia mossambica) using xylocaine with sodium bicarbonate $[\mathrm{PhD}$ Thesis]. Universidad Nacional Autonoma de Mexico Fac de Med Vet Zootec. 33 p. (1983)

[10] Harvey, B., Denny, C., Kaiser, S., ve Young, J., Remote intramuscular injection of immobilising drugs into fish using a laser-aimed underwater dart gun, Veterinary Record, 122(8), 174-177, (1988).

[11] Anju, T.D., Solomon, S.G., ve Cheikyula, J.O., Effects of aqueous leaf extract of tephropsia vogeli as a traquilizer on the african cat fish Heterobranchus longifilis val. (pisces 1840), American Journal of Research Communucation, 3(6), 4559, (2015).

[12] Knaak, N., ve Fiuza, L,M., Potencial dos óleos essenciais de plantas no controle de insetos e microrganismos, Neotropicol Biology and Conservation, 5, 120132, (2010).

[13] Mylonas, C.C., Cardinaletti, G., Sigelaki, I., ve Polzonetti-Magni, A., Comparative efficacy of clove oil and 2-phenoxyethanol as anesthetics in the aquaculture of European sea bass (Dicentrarchus labrax) and gilthead sea bream (Sparus aurata) at different temperatures, Aquaculture, 246(1-4), 467-481, (2005).

[14] Roohi, Z., ve Imanpoor, M.R., The efficacy of the oils of spearmint and methyl salicylate as new anesthetics and their effect on glucose levels in common carp (Cyprinus carpio L., 1758) juveniles. Aquaculture, 437, 327-332, (2015).

[15] Cihangir, E., ve Diler, İ., Yavru ve Jüvenil Gökkuşağı Alabalığı (Oncorhynchus mykiss, L.) yemlerine farklı oranlarda ilave edilen kekik (Origanum vulgare, L.) uçucu yağının büyüme performansı ve yemden yararlanma üzerine etkisi, Süleyman Demirel Üniversitesi Eğirdir Su Ürünleri Fakültesi Dergisi, 12(2), 86-96, (2016). 
[16] Metin, S., Didinen, B.I, Kubilay, A., Pala, M., ve Aker, İ.,. Bazı tıbbi bitkilerin Gökkuşağı Alabalıkları (Oncorhynchus mykiss Walbaum, 1792) Üzerinde anestezik etkilerinin belirlenmesi, Journal of Limnology and Freshwater Fisheries Research 1(1), 37-42, (2015).

[17] Samec, D., ve Piljac-Zegarac, J., Postharvest stability of antioxidant compounds in hawthorn and cornelian cherries at room and refrigerator temperaturescomparison with blackberries, white and red grapes, Scientia Horticulturae, 131, 15-21, (2011).

[18] Shakeri, A., Sahebkar, A., ve Javadi, B., Melissa officinalis L. - A review of its traditional uses, phytochemistry and pharmacology, Journal of Ethnopharmacology, 188, 204-228, (2016).

[19] Aksoy, L. Opium poppy (Papaver somniferum L.) oil for preparation of biodiesel: Optimization of conditions, Applied Energy, 88, 4713-4718, (2011).

[20] Albuquerque, U.P., Medeiros, P.M., Almeida, A.L.S., Monteiro, J.M., Neto, E.M.F.L., Melo, J.G., ve Santos, J.P., Medicinal plants of the caatinga (semi-arid) vegetation of NE Brazil: A quantitative approach, Journal of Ethnopharmacology, 114(3), 325-35, (2007).

[21] Taqi, A., Askar, K.A., Mutihac, L., ve Stamatin, I., Effect of Laurus nobilis L. oil, Nigella sativa L. oil and oleic acid on the antimicrobial and physical properties of subsistence agriculture: the case of cassava/pectin based edible films, Food and Agricultural Immunology, 24(2), 241-254, (2013).

[22] Atamanalp, M., ve Bayır, A., Bir Dezenfektanın (Malahit Yeşili) Subletal Dozlarının Gökkuşağı Alabalığı (Oncorhynchus mykiss) Kan Parametreleri Üzerine Etkileri, Gazi Üniversitesi Eğitim Fakültesi Dergisi, 23(3), 177-187, (2003).

[23] Soto, C.G., Burhanuddin, Clove oil as a fish anaesthetic for measuring length and weight of rabbitfish (Siganus lineatus), Aquaculture, 135, 149-152, (1995).

[24] Munday, P.L., ve Wilson, S.K.,. Comparative efficacy of clove oil and other chemicals in anaesthetization of Pomacentras amboinensis, a coral reef fish, Journal of Fish Biology, 51, 931-938, (1997).

[25] Imanpoor, M.R., Bagheri, T., ve Hedayeti, S.A.A., The anesthetic effects of clove essence in Persian sturgeon, Acipenser persicus, World Journal of Fish and Marine Sciences, 2(1), 29-36, (2010).

[26] Dolezelova, P., Macova, S., Plhalova, L., Pistekova, V., ve Svobodova, Z., The acute toxicity of clove oil to fish Danio rerio and Poecilia reticulata, Acta Veterinaria Brno, 80(3), 305-308, (2011).

[27] Ghazilou, A., ve Chenary, F., Evaluation of rosemary oil anesthesia in carp, Online Jornal of Veterinary Research, 15(2), 112-118, (2011).

[28] Silva, L.L., Parodi, T.V., Reckziegel, P., Garcia, V.O., Bürger, M.E., Baldisserotto, B., Malmann, C.A., Pereira, A.M.S., ve Heinzmann, B.M., Essential oil of Ocimum gratissimum: anesthetic effect, mechanism of action and tolerance in silver catfish (Rhamdia quelen), Aquaculture, 350-353, 91-97, (2012).

[29] Yıldız, M., Kayım, M., ve Akın, S., The anesthetic effects of clove oil and 2phenoxyethanol on rainbow trout (Oncorhynchus mykiss) at different concentrations and temperatures, Iranian Journal of Fisheries Sciences, 12(4), 947-961, (2013).

[30] El-Domiaty, N.A., Stress response of juvenile Clarias lazera elicited by copper, Comparative Biochemistry and Physiolology, C88 (2), 259-262, (1987). 
[31] Vosyliene, M.Z., Haematological parameters of rainbow trout (Oncorhynchus mykiss) during short-term exposure to copper, Ekologija, 3, 12-18, (1996).

[32] Van Vuren, J.H.J., Van der Merwe, M., ve Du Preez, H.H., The effect of copper on the blood chemistry of Clarias garlepinus (Clariidae), Ecotoxicology Environmental Safety, 29, 187-199, (1994).

[33] Vijayan, M.M., Pereira, C., Grau, E.G., ve Iwama, G.K., Metabolic responses associated with confinement stress in Tilapia; The Role of Cortisol, Comparative Biochemistry and Physiology, 116C, 1, 89-85, (1997).

[34] Zhiteneva, L.D., Poltavceva, T.G., Rudnickaja, O.A., Atlas of normal and pathological cells in the blood of fish. Rostov-on-Don, 112 pp. (1989).

[35] Gültepe, N., Balıklarda beslenme ile kan parametreleri arasındaki ilişkiler, Alınteri, 12 (B), 25-30, (2007).

[36] Keleştemur ,G.T., ve Özdemir,Y., Gökkuşağı Alabalığı (Oncorhynchus mykiss, W. 1792) yavrularının kortizol, glikoz ve bazı kan elektrolit değerleri üzerine anestezinin etkileri, Süleyman Demirel Üniversitesi Fen Bilimleri Enstitüsü Dergisi, 14(3), 213-217, (2010).

[37] Danli, J., Yubo, W., Di, H., Xing, R., ve Yan, W., Effect of blood glucose level on acute stress response of grass carp Ctenopharyngodon idella, Fish Physiology and Biochemistry, 43(5), 1433-1442, (2017).

[38] Pirhonen, J., ve Schreck, C.B., Effects of anaesthesia with MS-222, clove oil and $\mathrm{CO}_{2}$ on feed intake and plasma cortisol in steelhead trout (Oncorhynchus mykiss), Aquaculture, 220(1-4) , 14, 507-514, (2003).

[39] Knoph, M.B., ve Masoval, K., Plasma Ammonia and urea levels in Atlantic Salmon Farmed in Sea Water, Journal of Fish Biology, 49, 165-168, (1996).

[40] Karagül H, Altıntaş A, Fidancı UR, Sel, T., Klinik Biyokimya, Medisan Yayın Evi, Yayın No:45, s. 430(1), Ankara, (2000).

[41] Velisek, J., ve Svobodova, Z., Anaesthesia of Common Carp (Cyprinus carpio L.) with 2-Phenoxyethanol: acute toxicity and effects on biochemical blood profile, Acta Veterinaria, 73, 247-252, (2004).

[42] Simoes, L.N., Lombardi, D.C., Gomide, A.T.M., ve Gomes, L.C., Efficacy of clove oil as anesthetic in handling and transportation of Nile tilapia, Oreochromis niloticus (Actinopterygii: Cichlidae) juveniles, Zoologia, 28(3), 285-290, (2011).

[43] Davidson, G.W., Davie, P., Young, G., ve Fowler, R., Physiological Response of Rainbow Trout Oncorhynchus mykiss to Crowding and Anesthesia With AQUI-S, Journal of World Aquaculture Society, 31(1), 105-114, (2000).

[44] Velisek, J., Wlasow, T., Gomulka, P., Svobodova, Z., ve Novotny, L., Effects of 2-phenoxyethanol anaesthesia on Sheatfish (Silurus glanis L.), Veterinary Medicine, 52 (3),103-110, (2007).

[45] Azizoğlu, A., ve Cengizler, İ., Sağlıklı Oreochromis niloticus (L.) bireylerinde bazı hematolojik parametrelerin saptanması üzerine bir araştırma, Turkish Journal of Veterinary and Animal Sciences, 20, 425-431, (1996).

[46] Mayer, S., A review of the scientific justifications for maintaining cetaceans in captivity, (edit. By Frances Clarke), A report for the whale and dolphin conservation society (WDCS), 35 p., (1998).

[47] Demir, N., İhtiyoloji, İstanbul Üniversitesi Fen Fakültesi Basımevi, Cilt No. 2, İstanbul, 365 s. (1996).

[48] Ryan, S., The dynamics of MS-222 anaesthesia in a marine teleost (Pagrus auratus: Sparidae), Comporative Biochemistry and Physiology Part C, 101(3), 593-600, (1992). 